\title{
Regression model for fluid flow in a static mixer
}

\author{
Rajamanickam Akila ${ }^{1}$,Kumar Balu ${ }^{2}$ \\ ${ }^{l}$ Department of Mathematics, Anna University, Chennai, India. ${ }^{2}$ Department of Chemical Engineering, Anna University, \\ Chennai, India. Article Info: Submitted on March 2, 2015, Accepted on August 12, 2015.
}

\begin{abstract}
A regression model for simulating residence time distribution (RTD) of turbulent flows in helical static mixers is proposed and developed to predict the residence time distribution in static mixers. An efficient method is required to estimate the RTD and the sole means of achieving this is through detailed regression model. The RTD was calculated numerically by regression model. The results of the regression model, i.e. predicted RTD is presented in terms of different volumetric flow rate to illustrate the complicated flow patterns that drive the mixing process in helical static mixers. The regression model is found to fit the experimental RTD with a high degree of correlation.
\end{abstract}

Keywords: Regression model; Resident time distribution; Static mixer; Tubular reactor.

\section{Introduction}

Process industries include all those operations where the feed materials undergo chemical or physiochemical changes during the manufacture of end products. The majority of unit operations that serve these material transformations are basically mixing or separation in nature. Chemical treatment steps are conducted in vessels known as reactors, which are stirred tank reactors (backmix reactors) and plug flow reactors. Actual reactors deviate from these idealized concepts. The deviation is due to non-uniform velocity profile, velocity fluctuation due to molecular or turbulent diffusion, short circuiting of fluid elements, bypassing and channeling, presence of stagnant regions due to reactor shape and internals, and recycling of fluid elements within the reactor as a result of agitation. The discrete (stage-wise) backmixing model was considered as the best model representing residence time behavior in the small-scale tube. ${ }^{1}$ Mathematical modeling coupled with rigorous statistical methods has been of great assistance in understanding and quantifying the flow in a reactor as it is critical for predicting performance of the reactor.

Actual reactors deviate from these idealized concepts. The deviation is due to non - uniform velocity profile, velocity fluctuation due to molecular or turbulent diffusion, short circuiting of fluid elements, bypassing and channeling, presence of stagnant regions due to reactor as result of agitation etc. As mentioned earlier, the plug flow reactor having many advantages over backmix reactor is centered on a fact that the movement of each particle is always forward in the form of a 'file' and no backmixing is allowed. The residence time of each fluid elements flow in the form of a 'file'. To establish such a situation in actual reactors, the fluid flow through the tube must be under turbulent conditions.
A list of commercial static mixers and their applications has been described in literature. ${ }^{2-7}$ Large Eddy simulations of a compressible turbulent flow through a duct of square cross-section with a discrete heating source is presented in litarature. ${ }^{8,9}$ The performance of a newly developed Centrifugal Phase Separator (CPS) is investigated using RANS-based two-phase computational fluid dynamics (CFD) and experimental model studies. The cyclone separator consists of two volutes (inlet and outlet) connected with a cylindrical tower; recirculation of the flow within the tower ensures adequate centrifugal forces for phase separation. Numerical calculations are performed using the commercial CFD code FLUENT for different mesh types, turbulence models, advection schemes, and mesh resolution. ${ }^{1,10}$ Assessment of aerodynamics in the space between tubes of the fluidized boiler is available in litarature. ${ }^{11-13}$ Numerically elucidated the velocity Beld, pressure drop and residence time distribution of the static mixers. ${ }^{14-19}$ Most related works considered the aspect of macro-mixing, by elucidating the residence time distribution (RTD) of mixers. ${ }^{2,4,520}$ RTD cannot properly reflect the complicated flow characteristics in the static mixers. ${ }^{19}$ As the flow of fluids through a static mixer undergoes three types mechanisms, namely: (a) flow division, (b) flow reversal and (c) flow combination.

Due to continuous flow division, flow reversal and flow combination at every element of the mixer the parabolic velocity profile cannot get established and therefore ideal plug flow conditions are approached. Hence the static mixer can be utilized for any process application of tubular chemical reactors where the provision of narrow residence time is important. We also need efficient methods to estimate the RTD and the sole means of achieving this is through detailed 


\section{Chemical Engineering Research Bulletin 18(2015) 23-29}

regression model. Such theoretical estimates need, however, always to be thoroughly checked against observations in Static mixer. This is a rather difficult task, since methods to estimate RTD from observations are not unique and can be subjected to strong criticism. The RTD was calculated numerically by the Regression model. The results of the regression model - the predicted RTD - are presented in terms of different volumetric flow rate to illustrate the complicated flow patterns that drive the mixing process in helical static mixers.

\section{Materials and Methods}

The equipment consists of an outer pyrex tube of 1210 $\mathrm{mm}$ in length and $35 \mathrm{~mm}$ inner diameter provided with two inlets at one end opposite to each other and inclined at $45^{\circ}$ with the axis of the tube. The inlet is 15 $\mathrm{mm}$ in diameter. Four intermediate outlets are provided at $212 \mathrm{~mm}$ apart, along the length of the tube. These exits serve as manometer tapings for pressure drop experiments and would be used to turn out reactor effluent at intermediate length of the tube when conversion experiments are carried out. Alternatively, they would also be used to insert thermometer with slight modification, when the heat transfer experiments are conducted. Those exits not in use are normally kept closed by spring-type inch cocks on flexible rubber tube fitted on to the side exits.

Concentric with the outer pyrex tube is an inner tube of $22.4 \mathrm{~mm}$ outer diameter, $18.5 \mathrm{~mm}$ inner diameter. A brass flange brazed to the tube is bolted to a corresponding perpex flange, fastened to the pyrex tube with an adhesive. Fig. 1 shows the unit with mixing elements. To the brass tube the helical elements are brazed. Each element consists of two 0.8 $\mathrm{mm}$ brass sheets $6.2 \mathrm{~mm}$ wide, carefully cut and twisted to form part of a helix of $60 \mathrm{~mm}$ pitch. The elements are of half a pitch in length i.e. $30 \mathrm{~mm}$. These are brazed to the outer circumference of the tube $180^{\circ}$ apart, alternative elements are right-handed and lefthanded and each one is at right angles to the adjacent ones. In all, the reactor contains thirty five elements, seventeen left-handed and eighteen right-handed.

The tracer is introduced into the reactor inlet. A hypodermic needle No.22 is used to inject $1 \mathrm{ml}$ of tracer (nearly $5 \mathrm{~N}$ Sodium Chloride solution) in the reactor inlet. Samples of reactor effluent are collected at frequent intervals (of 5 seconds). From the quantity of sample collected, a small quantity of sample $(10 \mathrm{ml})$ is titrated against a $0.05 \mathrm{~N}$ silver nitrate solution. The volume of silver nitrate consumed is directly proportional to the concentration of sodium chloride solution in the outlet stream. The sample collection is done for sufficient time interval (for $\mathrm{t}>5 \mathrm{E}$, where $\mathrm{E}$ is the average retention time). The above experiments are repeated until concordant liter values are obtained. The flow rate is then varied and the above mentioned procedure is repeated. For the annulus with mixing elements the flow rate range covered is $40-120 \mathrm{liter} / \mathrm{hr}$, as above $120 \mathrm{liter} / \mathrm{hr}$, the average retention time was very low to detect any appreciable change in concentration within the time intervals of collection period. In order to determine the RTD $(\mathrm{E}(\theta))$ for the Static mixer, we consider a simpler situation where perfect mixing, constant density, steady state etc. prevails.

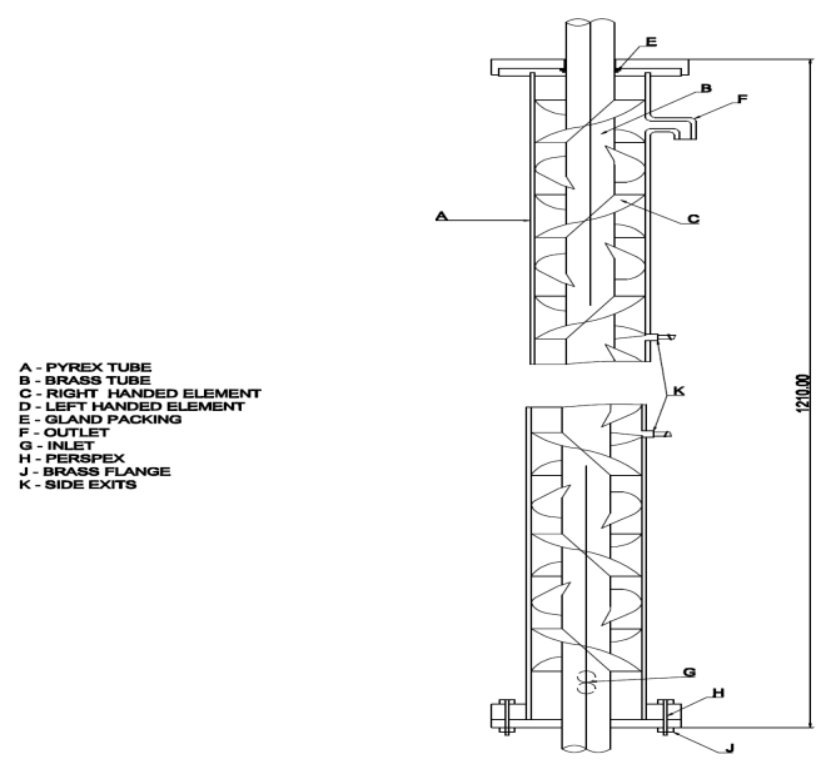

Figure 1: Tubular flow reactor with helical mixing elements.

\section{The regression model}

Regression analysis methodology is a mathematical technique useful for developing, improving, and optimizing processes. A generalized linear model is a regression model, made up of a random component $(\varepsilon)$, a linear function of the design factors $(\mathrm{C}, \theta)$, and the unknown regression parameters $(\beta \mathrm{i})$. In our case, a constant $\beta 0$, and 2 design factors, $C$ and $\theta$, are required to compute RTD. The regression equation of RTD is

$$
\hat{E}(\theta)=\beta_{0}+\beta_{1} C+\beta_{2} \theta+\beta_{11} C^{2}+\beta_{22} \theta^{2}+\beta_{12} C \theta+\varepsilon
$$

where $\hat{E}(\theta)$ is residence time distribution, $\beta_{0}$ is a constant, $\mathrm{C}$ is the first design factor (concentration of the solution), $\theta$ is the second design factor (residence time). The natural unit values of $C$ and $\theta$ are coded as variables $X_{1}$ and $X_{2}$ respectively. 


\section{Chemical Engineering Research Bulletin 18(2015) 23-29}

Table 1: Regression Equation with various Volumetric Flow Rates for Residence time distribution of Turbulent Reactor with Brazed Helical element

\begin{tabular}{|c|c|c|}
\hline Sl.No. & $\begin{array}{l}\text { Volumetric } \\
\text { Flow Rate }\end{array}$ & $\begin{array}{l}\text { Regression equation of Residence time distribution } \hat{E}(\theta) \text { with code variable and natural } \\
\text { variable }\end{array}$ \\
\hline 1 & $40 l / h r$ & $\begin{array}{l}\hat{E}(\theta)=1.1421+1.1428 X_{1}+0.0024 X_{2}+0.0003 X_{1}^{2}+0.0009 X_{2}^{2}+0.0027 X_{1} X_{2} \\
\hat{E}(\theta)=-0.0046+0.7158 C+0.0006 \theta+0.0001 C^{2}+0.0003 \theta^{2}+0.0009 C \theta\end{array}$ \\
\hline 2 & $601 / h r$ & $\begin{array}{l}\hat{E}(\theta)=1.3246+1.3241 X_{1}-0.0011 X_{2}-0.001 X_{1}^{2}-0.0004 X_{2}^{2}-0.002 X_{1} X_{2} \\
\hat{E}(\theta)=-0.0018+0.6205 C+0.0005 \theta+0.0002 C^{2}+0.00004 \theta^{2}+0.0003 C \theta\end{array}$ \\
\hline 3 & $80 l / h r$ & $\begin{array}{l}\hat{E}(\theta)=1.2981+1.2970 X_{1}-0.0025 X_{2}-0.0016 X_{1}^{2}-0.0017 X_{2}^{2}-0.0046 X_{1} X_{2} \\
\hat{E}(\theta)=-0.0457+0.4344 C+0.0178 \theta+0.0002 C^{2}+0.0002 \theta^{2}-0.0051 C \theta\end{array}$ \\
\hline 4 & $100 / / h r$ & $\begin{array}{l}\hat{E}(\theta)=1.2662+1.2643 X_{1}-0.0037 X_{2}-0.0031 X_{1}^{2}-0.0021 X_{2}^{2}-0.007 X_{1} X_{2} \\
\hat{E}(\theta)=-0.0066+0.4331 C+0.0027 \theta-0.0004 C^{2}-0.0003 \theta^{2}-0.0009 C \theta\end{array}$ \\
\hline 5 & $120 l / h r$ & $\begin{array}{l}\hat{E}(\theta)=1.4846+1.4822 X_{1}-0.0117 X_{2}-0.0026 X_{1}^{2}-0.0006 X_{2}^{2}-0.0125 X_{1} X_{2} \\
\hat{E}(\theta)=-0.0016+0.4286 C+0.0009 \theta-0.0002 C^{2}-0.0001 \theta^{2}-0.0002 C \theta\end{array}$ \\
\hline
\end{tabular}

Table 2: Experimental RTD and Simulated RTD in Annulus with Mixing Elements of Volumetric Flow Rate $=40$ $1 / \mathrm{hr}$

\begin{tabular}{|c|c|c|c|c|c|c|c|c|c|c|}
\hline $\begin{array}{l}\text { Sl. } \\
\text { No. }\end{array}$ & $\begin{array}{c}\text { Concentra- } \\
\text { tion }(\mathrm{C})\end{array}$ & $\begin{array}{c}\text { Time(t) } \\
(\mathrm{Sec})\end{array}$ & $\begin{array}{c}\text { Residence } \\
\operatorname{time}(\theta)\end{array}$ & $\begin{array}{c}\text { Experi- } \\
\text { mental } \\
\text { RTD } \\
\text { E }(\theta)\end{array}$ & $X_{1}$ & $X_{2}$ & $X_{1}^{2}$ & $X_{2}^{2}$ & $X_{1} X_{2}$ & $\begin{array}{l}\text { Simulated } \\
\text { RTD } \\
\hat{E}(\theta)\end{array}$ \\
\hline 1 & 0.399 & 0 & 0 & 0.285 & -0.75055 & -1 & 0.563321 & 1 & 0.750547 & 0.281023 \\
\hline 2 & 2.5 & 10 & 0.385287 & 1.783 & 0.562988 & -0.78947 & 0.316956 & 0.623266 & -0.44446 & 1.786793 \\
\hline 3 & 3.199 & 15 & 0.57793 & 2.282 & 1 & -0.68421 & 1 & 0.468141 & -0.68421 & 2.288585 \\
\hline 4 & 2.799 & 20 & 0.770574 & 1.997 & 0.749922 & -0.57894 & 0.562383 & 0.335177 & -0.43416 & 2.002455 \\
\hline 5 & 2.199 & 25 & 0.963217 & 1.569 & 0.374805 & -0.47368 & 0.140479 & 0.224373 & -0.17754 & 1.572797 \\
\hline 6 & 1.899 & 30 & 1.15586 & 1.355 & 0.187246 & -0.36842 & 0.035061 & 0.135731 & -0.06898 & 1.358211 \\
\hline 7 & 1.099 & 40 & 1.541147 & 0.784 & -0.31291 & -0.15789 & 0.097913 & 0.024929 & 0.049405 & 0.785345 \\
\hline 8 & 0.698 & 50 & 1.926434 & 0.499 & -0.56361 & 0.052639 & 0.31766 & 0.002771 & -0.02967 & 0.4985 \\
\hline 9 & 0.5 & 55 & 2.119077 & 0.356 & -0.6874 & 0.157902 & 0.472522 & 0.024933 & -0.10854 & 0.356809 \\
\hline 10 & 0.399 & 60 & 2.311721 & 0.285 & -0.75055 & 0.263166 & 0.563321 & 0.069257 & -0.19752 & 0.284724 \\
\hline 11 & 0.299 & 65 & 2.504364 & 0.213 & -0.81307 & 0.36843 & 0.661077 & 0.135741 & -0.29956 & 0.213345 \\
\hline 12 & 0.199 & 70 & 2.697008 & 0.142 & -0.87559 & 0.473694 & 0.766651 & 0.224386 & -0.41476 & 0.141952 \\
\hline 13 & 0.199 & 75 & 2.889651 & 0.142 & -0.87559 & 0.578958 & 0.766651 & 0.335192 & -0.50693 & 0.142395 \\
\hline 14 & 0.099 & 85 & 3.274938 & 0.071 & -0.93811 & 0.789486 & 0.880042 & 0.623288 & -0.74062 & 0.071457 \\
\hline 15 & 0 & 95 & 3.660225 & 0 & -1 & 1.000014 & 1 & 1.000027 & -1.00001 & 0.00125 \\
\hline
\end{tabular}

Table 3: Experimental RTD Studies and Simulated RTD in Annulus with Mixing Elements of Volumetric Flow Rate $=601 / \mathrm{hr}$

\begin{tabular}{|c|c|c|c|c|c|c|c|c|c|c|}
\hline $\begin{array}{l}\text { Sl. } \\
\text { No. }\end{array}$ & $\begin{array}{l}\text { Concentra- } \\
\text { tion }(C)\end{array}$ & $\begin{array}{l}\text { Time }(\mathrm{t}) \\
(\mathrm{Sec})\end{array}$ & $\begin{array}{l}\text { Residence } \\
\text { time }(\theta)\end{array}$ & $\begin{array}{l}\text { Experi- } \\
\text { mental } \\
\text { RTD } \\
\text { E }(\theta)\end{array}$ & $X_{1}$ & $\mathrm{X}_{2}$ & $X_{1}^{2}$ & $X_{2}^{2}$ & $X_{1} X_{2}$ & $\begin{array}{l}\text { Simulated } \\
\operatorname{RTD} \hat{E}(\theta)\end{array}$ \\
\hline 1 & 1.6 & 0 & 0 & 0.986 & -0.25581 & -1 & 0.065441 & 1 & 0.255814 & 0.990437 \\
\hline 2 & 4.3 & 5 & 0.5 & 2.65 & 1 & -0.84615 & 1 & 0.715976 & -0.84615 & 2.661933 \\
\hline 3 & 4 & 10 & 1 & 2.465 & 0.860465 & -0.69231 & 0.7404 & 0.47929 & -0.59571 & 2.476088 \\
\hline 4 & 2.5 & 15 & 1.5 & 1.541 & 0.162791 & -0.53846 & 0.026501 & 0.289941 & -0.08766 & 1.547868 \\
\hline 5 & 1.5 & 20 & 2 & 0.924 & -0.30233 & -0.38462 & 0.091401 & 0.147929 & 0.116279 & 0.928797 \\
\hline 6 & 0.5 & 25 & 2.5 & 0.308 & -0.76744 & -0.23077 & 0.588967 & 0.053254 & 0.177102 & 0.309595 \\
\hline 7 & 0.1 & 35 & 3.5 & 0.061 & -0.95349 & 0.076923 & 0.90914 & 0.005917 & -0.07335 & 0.062467 \\
\hline 8 & 0 & 45 & 4.5 & 0 & -1 & 0.384615 & 1 & 0.147929 & -0.38462 & 0.001355 \\
\hline 9 & 0 & 55 & 5.5 & 0 & -1 & 0.692308 & 1 & 0.47929 & -0.69231 & 0.002265 \\
\hline 10 & 0 & 65 & 6.5 & 0 & -1 & 1 & 1 & Ban 1 lad & hUnitioft & 8.90325125 \\
\hline
\end{tabular}




\section{Chemical Engineering Research Bulletin 18(2015) 23-29}

Table 4: Experimental RTD Studies and Simulated RTD in Annulus with Mixing Elements of Volumetric Flow Rate $=801 / \mathrm{hr}$

\begin{tabular}{|c|c|c|c|c|c|c|c|c|c|c|}
\hline $\begin{array}{l}\text { Sl. } \\
\text { No. }\end{array}$ & $\begin{array}{l}\text { Concentra- } \\
\text { tion }(\mathrm{C})\end{array}$ & $\begin{array}{l}\text { Time }(\mathrm{t}) \\
(\mathrm{Sec})\end{array}$ & $\begin{array}{l}\text { Residence } \\
\operatorname{time}(\theta)\end{array}$ & $\begin{array}{l}\text { Experi- } \\
\text { mental } \\
\text { RTD } \\
\text { E }(\theta)\end{array}$ & $\mathrm{X}_{1}$ & $\mathrm{X}_{2}$ & $X_{1}^{2}$ & $X_{2}^{2}$ & $X_{1} X_{2}$ & $\begin{array}{l}\text { Simulated } \\
\text { RTD } \hat{E}(\theta)\end{array}$ \\
\hline 1 & 2.5 & 0 & 0 & 1.047 & -0.19355 & -1 & 0.037461 & 1 & 0.193548 & 1.041363 \\
\hline 2 & 6.2 & 5 & 0.649789 & 2.598 & 1 & -0.77778 & 1 & 0.604938 & -0.77778 & 2.645219 \\
\hline 3 & 4.2 & 10 & 1.299578 & 1.76 & 0.354839 & -0.55556 & 0.125911 & 0.308642 & -0.19713 & 1.777412 \\
\hline 4 & 1.6 & 15 & 1.949367 & 0.67 & -0.48387 & -0.33333 & 0.234131 & 0.111111 & 0.16129 & 0.669327 \\
\hline 5 & 0.6 & 20 & 2.599156 & 0.251 & -0.80645 & -0.11111 & 0.650364 & 0.012346 & 0.089606 & 0.254664 \\
\hline 6 & 0.2 & 30 & 3.898734 & 0.084 & -0.93548 & 0.333334 & 0.87513 & 0.111111 & -0.31183 & 0.109648 \\
\hline 7 & 0.1 & 35 & 4.548523 & 0.042 & -0.96774 & 0.555556 & 0.936524 & 0.308642 & -0.53763 & 0.080523 \\
\hline 8 & 0 & 40 & 5.198312 & 0 & -1 & 0.777778 & 1 & 0.604939 & -0.77778 & 0.052234 \\
\hline 9 & 0 & 45 & 5.848101 & 0 & -1 & 1 & 1 & 1.000001 & -1 & 0.065236 \\
\hline
\end{tabular}

Table 5: Experimental RTD Studies and Simulated RTD in Annulus with Mixing Elements of Volumetric Flow Rate $=100$ l/hr

\begin{tabular}{|c|c|c|c|c|c|c|c|c|c|c|}
\hline $\begin{array}{l}\text { Sl. } \\
\text { No. }\end{array}$ & $\begin{array}{l}\text { Concentra- } \\
\text { tion(C) }\end{array}$ & $\begin{array}{l}\text { Time }(\mathrm{t}) \\
(\mathrm{Sec})\end{array}$ & $\begin{array}{l}\text { Residence } \\
\text { time }(\theta)\end{array}$ & $\begin{array}{l}\text { Experi- } \\
\text { mental } \\
\text { RTD } \\
\text { E }(\theta)\end{array}$ & $X_{1}$ & $X_{2}$ & $X_{1}^{2}$ & $X_{2}^{2}$ & $X_{1} X_{2}$ & $\begin{array}{l}\text { Simulated } \\
\text { RTD } \\
\hat{E}(\theta)\end{array}$ \\
\hline 1 & 2.6 & 0 & 0 & 1.117 & $\stackrel{-}{-}$ & -1 & 0.014076 & 1 & 0.118644 & 1.117026 \\
\hline 2 & 5.9 & 5 & 0.778481 & 2.534 & 1 & -0.71429 & 1 & 0.510207 & -0.71429 & 2.534126 \\
\hline 3 & 2.5 & 10 & 1.556962 & 1.074 & 0.15254 & -0.42857 & 0.023269 & 0.183676 & 0.065376 & 1.074101 \\
\hline 4 & 0.7 & 15 & 2.335443 & 0.3 & $\begin{array}{c}- \\
0.76271\end{array}$ & -0.14286 & 0.581729 & 0.02041 & 0.108963 & 0.299843 \\
\hline 5 & 0.3 & 20 & 3.113924 & 0.128 & $\begin{array}{c}- \\
0.89831\end{array}$ & 0.14285 & 0.806952 & 0.020406 & -0.12832 & 0.128302 \\
\hline 6 & 0.2 & 25 & 3.892405 & 0.086 & -0.9322 & 0.428563 & 0.869003 & 0.183666 & -0.39951 & 0.085751 \\
\hline 7 & 0.1 & 30 & 4.670886 & 0.043 & -0.9661 & 0.714275 & 0.933352 & 0.510189 & -0.69006 & 0.042989 \\
\hline 8 & 0 & 35 & 5.449367 & 0 & -1 & 0.999988 & 1 & 0.999976 & -0.99999 & 0.00 \\
\hline
\end{tabular}

Table 6: Experimental RTD Studies and Simulated RTD in Annulus with Mixing Elements of Volumetric Flow Rate $=1201 / \mathrm{hr}$

\begin{tabular}{|c|c|c|c|c|c|c|c|c|c|c|}
\hline $\begin{array}{l}\text { Sl. } \\
\text { No. }\end{array}$ & $\begin{array}{l}\text { Concentra- } \\
\operatorname{tion}(\mathrm{C})\end{array}$ & $\begin{array}{l}\text { Time }(\mathrm{t}) \\
(\mathrm{Sec})\end{array}$ & $\begin{array}{l}\text { Residence } \\
\operatorname{time}(\theta)\end{array}$ & $\begin{array}{l}\text { Experi- } \\
\text { mental } \\
\text { RTD E }(\theta)\end{array}$ & $\mathrm{X}_{1}$ & $\mathrm{X}_{2}$ & $X_{1}^{2}$ & $X_{2}^{2}$ & $X_{1} X_{2}$ & $\begin{array}{l}\text { Simulated } \\
\text { RTD } \\
\hat{E}(\theta)\end{array}$ \\
\hline 1 & 0.3 & 0 & 0 & 0.127 & $\begin{array}{c}- \\
0.91429\end{array}$ & -1 & 0.835918 & 1 & 0.914286 & 0.126961 \\
\hline 2 & 7 & 5 & 0.744526 & 2.98 & 1 & -0.66667 & 1 & 0.444449 & -0.66667 & 2.980575 \\
\hline 3 & 2.2 & 10 & 1.489051 & 0.936 & $\stackrel{-}{-} 0.37143$ & -0.33334 & 0.137959 & 0.111116 & 0.123812 & 0.936136 \\
\hline 4 & 0.5 & 15 & 2.233577 & 0.212 & $\begin{array}{c}- \\
0.85714\end{array}$ & $-1 \mathrm{E}-05$ & 0.734694 & $1.06 \mathrm{E}-10$ & 8.83E-06 & 0.212272 \\
\hline 5 & 0.2 & 20 & 2.978102 & 0.085 & $\begin{array}{c}- \\
0.94286\end{array}$ & 0.333319 & 0.88898 & 0.111102 & -0.31427 & 0.084775 \\
\hline 6 & 0 & 25 & 3.722628 & 0 & -1 & 0.666649 & 1 & 0.444421 & -0.66665 & 0.0001 \\
\hline 7 & 0 & 30 & 4.467153 & 0 & -1 & 0.999979 & 1 & 0.999958 & -0.99998 & 0.0000 \\
\hline
\end{tabular}




$$
\begin{aligned}
& X_{i 1}=\frac{C_{i 1}-\left[\max \left(C_{i 1}\right)+\min \left(C_{i 1}\right)\right] / 2}{\left[\max \left(C_{i 1}\right)-\min \left(C_{i 1}\right)\right] / 2} \\
& X_{i 2}=\frac{\theta_{i 1}-\left[\max \left(\theta_{i 1}\right)+\min \left(\theta_{i 1}\right)\right] / 2}{\left[\max \left(\theta_{i 1}\right)-\min \left(\theta_{i 1}\right)\right] / 2}
\end{aligned}
$$

Hence the fit model become

$$
\hat{E}(\theta)=\beta_{0}+\beta_{1} X_{1}+\beta_{2} X_{2}+\beta_{11} X_{1}^{2}+\beta_{22} X_{2}^{2}+\beta_{12} X_{1} X_{2}+\varepsilon
$$

The least squares estimate of $\beta$ is $\beta=\left(X^{\prime} X\right)^{-1} X^{\prime} E(\theta)$

where $X$ is a matrix of the levels of the independent variables (concentration and residence time), $E(\theta)$ is the column vector of the experimental residence time distribution.

Table 1 shows that the least squares fit with code variables and natural variables for different volumetric flow rate $(401 / \mathrm{hr}-120 \mathrm{l} / \mathrm{hr})$. Tables $2-6$ shows the coding scheme used in fitting linear regression models and it results in all the values of $X_{1}$ and $X_{2}$ falling between -1 and +1 and the simulated value of residence time distribution by regression model (for different volumetric flow rate).

\section{Results and Discussion}

The determination of $E(\theta)$ for various values of experimental $\theta \mathrm{s}$ for turbulent reactor with blazed helical element involves the solution of regression equation. Comparison of RTD curves between simulations and experimental data for an amplification of different volumetric flow rates in tubular reactor with brazed helical element are as given in Fig. 2. This gives the comparison of the measured and the simulated values from the application of the regression model. From Fig. 2, infer that the change in Residence time distribution (RTD) calculated using the simulated values and experimental values agree well. Dynamical behavior of the RTD as a function of residence time is described by the regression model for various volumetric flow rate.

Detailed comparisons of the measured and predicted RTD have been made and these comparisons show that the model captures the growth and evolution of the RTD and its subsequent distortion. The model also predicts a slower than measured recovery of the RTD. The agreement between the predicted and measured RTD is excellent. This work quantitatively measures the micro-mixing efficiency in a static mixer.
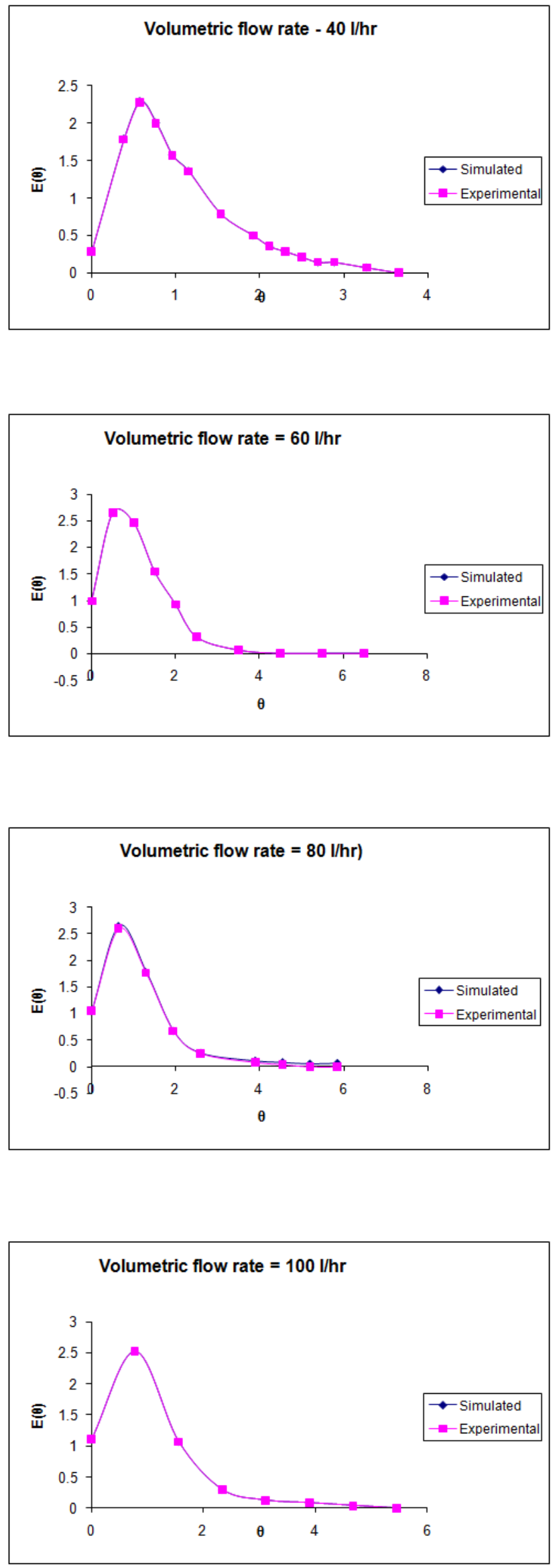


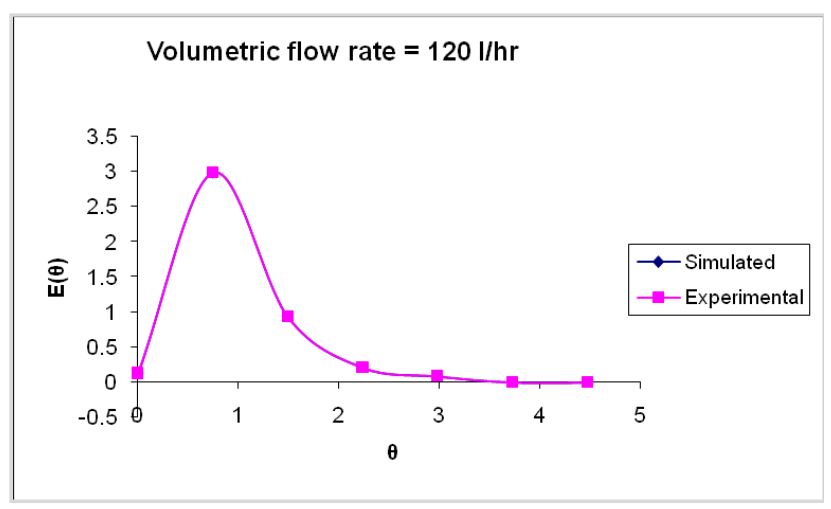

Figure 2: Comparison of RTD curves between simulation and experimental data with brazed helical element of various volumetric flow rates.

\section{Conclusion}

Detailed comparisons of the measured and predicted RTD Residence time distribution (RTD) studies were performed in tubular flow reactor with motionless mixing elements. In this paper, Regression model simulations for the prediction of RTD for fluid flow in a tubular reactor with static mixer. The theoretical RTD results obtained from the application of the regression model have been compared with the results obtained by performing the experiments in tubular reactor with Static mixer. The experimental and computational evidence of RTD in Static mixer is provided in this paper. The comparison is commonly scaled to the minimum standard error which yields the result that the regression model simulated results are good fit to the experimental data. The comparison validates our synthetic modeling and shows that the regression model is the best model to predict RTD for Static mixer. The fact proves that the model is best suited for our target applications.

\section{Acknowledgement}

This research was made possible by my beloved guide Dr. K. Balu, Rtd. Professor and Director, Department of Chemical Engineering, Anna University, Chennai.

\section{References}

1. N. Reis, "The use of fibre optic probes for flow monitoring within a small-scale tube", 3rd International Symposium on Two-Phase Flow Modelling and Experimentation Pisa, September 2004, pp. 22-24.

2. Z. Kemblowski and P. Pustelnik, "Residence time distribution of a power-law fluid in Kenics static mixers", Chemical Engineering Science, 1988, 43, pp. 473-478.

3. W. D. Morris and P. Misson, "An Experimental Investigation of Mass Transfer and Flow Resistance in the Kenics Static Mixer", Ind. Eng. Chem. Process Des. Dev., 1974, 13, pp. 270.

4. E. B. Nauman, "On residence time and trajectory calculations in motionless mixers", The Chemical Engineering Journal, 1991, 47, pp. 141-148.

5. K. D. P. Nigam and K. Vasudeva, "Residence time distributions in static mixers", Canadian Journal of Chemical Engineering, 1980, 58, pp. 543-544.

6. D. A. Pattison, "Motionless Inline Mixers Stir Up Broad Interest", Chem. Eng., May 1969, 19, pp. 94-96.

7. L. L. Simpson, "Turbulence and Industrial Mixing", Chem. Eng. Prog., 1974, 70, pp. 77.

8. E. W. Pitera and S. Middleman, "Convection Promotion in Tubular Desalination Membranes", Ind. Eng. Chem. Process Des. Develop, vol.12, pp. 52, 1973.

9. S. E. Alimi, C. Münch, A. Azzi, P. Bégou and S. B. Nasrallah, "Large Eddy Simulation of a Compressible Flow in a Locally Heated Square Duct", International review of modelling and simulation, February 2009, 2(1), pp. 93-97.

10. P.I. Kefalas and D. P. Margaris, "CFD Simulation and Experimental Verification of the Flow Field in a Centrifugal Separator, International review of modelling and simulation", August 2009, 2,(4), pp. 472-478.

11. A. Amirtharajah and S. C. Jones, "Mixing for coagulation: Organic polymers, static mixers and modeling," Chemical water and wastewater treatment IV, Springer-Verlag, 1996.

12. H. Zildžo, R. Gačanović and H. Matoruga, "Calculation of Cooling Massive Conductors with Finite Element Method in Fluid Dynamics, International review of modelling and simulation", August 2010, 3(4): pp. 739-745.

13. J. Wydrych and N. Szmolke, "Reciprocal Correlations in Fluid Flows, International review of modelling and simulation", International review of modelling and simulation, October 2010(b), 3(5), pp. 1116-1128.

14. J. Arimond and L. Erwin, "A simulation of motionless mixer, Chemical Engineering Communication", 1985, 37, pp. 105-126.

15. D. M. Hobbs and F. J . Muzzio, "The Kenics static mixer: a three-dimensional chaotic flow", Chemical Engineering Journal, 1997a, 67, pp. 153-166.

16. D. M. Hobbs and F. J. Muzzio, "Effects of injection location, flow ratio and geometry on Kenics mixer performance", A.I.Ch.E. Journal, 1997b, 43, pp. 3121-3132. 


\section{Chemical Engineering Research Bulletin 18(2015) 23-29}

17. D. M. Hobbs and F. J. Muzzio, "Optimization of a static mixer using dynamical systems techniques", Chemical Engineering Science, 1998, 53, pp. 3199-3213.

18. D. M. Hobbs, P. D. Swanson and F. J. Muzzio, "Numerical characterization of low Reynolds number flow in the Kenics static mixer", Chemical Engineering Science, 1998, 53, pp. 1565-1584.

19. D. V. Khakhar, J. G. Franjione and J. M. Ottino, "A case study of chaotic mixing in deterministic flows: The partitioned-pipe mixer", Chemical Engineering Science, 1987, 42, pp. 2909-2926.

20. E. B. Nauman, "Reactions and residence time distributions in motionless mixers", Canadian Journal of Chemical Engineering, 1982, 60, pp. $136-140$.

\section{Available online at http://www.banglajol.info/index.php/CERB}

